\title{
A differential diagnosis of a head and neck bony lesion : Review of a case series with 18 patients with extraintestinal features of familial adenomatous polyposis
}

\section{Dickinson, A.}

2018-06

Dickinson , A, Koskenvuo , L , Tuomainen , K, Makitie , A, Lepisto , A \& Renkonen , S 2018 , ' A differential diagnosis of a head and neck bony lesion : Review of a case series with 18 patients with extraintestinal features of familial adenomatous polyposis ' , Clinical Otolaryngology , vol. 43 , no. 3 , pp. 928-931 . https://doi.org/10.1111/coa.13062

http://hdl.handle.net/10138/302420

https://doi.org/10.1111/coa.13062

publishedVersion

Downloaded from Helda, University of Helsinki institutional repository.

This is an electronic reprint of the original article.

This reprint may differ from the original in pagination and typographic detail.

Please cite the original version. 
Correspondence

H. Mohammed, ENT Department, Norfolk and Norwich University Hospital NHS Trust, Norwich, NR4 7UY, UK.

Email: hmohammed@nhs.net

\section{REFERENCES}

1. Hecht J. City of light: the story of fiber optics / Jeff Hecht. New York: Oxford University Press; 1999.

2. Fleming JC, Al-Radhi Y, Kurian A, Mitchell DB. Comparative study of flexible nasoendoscopic and rigid endoscopic examination for patients with upper aerodigestive tract symptoms. J Laryngol Otol. 2013;127:1012-1016.

3. Bertino G, Cacciola S, Fernandes WB Jr, et al. Effectiveness of narrow band imaging in the detection of premalignant and malignant lesions of the larynx: validation of a new endoscopic clinical classification. Head Neck. 2015;37:215-222.
4. McGarey PO Jr, O'Rourke AK, Owen SR, et al. Rlgid esophagoscopy for head and neck cancer staging and the incidence of synchronous esophageal malignant neoplasms. JAMA. 2016;142:40-45.

5. Belafsky PC, Postma GN, Koufman JA. Normal transnasal esophagoscopy. Ear Nose Throat J. 2001;80:438.

6. Aviv JE, Takoudes TG, Ma G, Close LG. Office-based esophagoscopy: a preliminary report. Otolaryngol Head Neck Surg. 2001;125:170-175.

7. Belafsky PC, Postma GN, Daniel E, Koufman JA. Transnasal esophagoscopy. Otolaryngol Head Neck Surg. 2001;125:588-589.

8. Price T, Sharma A, Snelling J., et al. How we do it: the role of transnasal flexible laryngo-oesophagoscopy (TNFLO) in ENT: One year's experience in a head neck orientated practice in the UK. Clin Otolaryngol. 2005;30:551-556

9. Ahuja NK, Chan WW. Assessing upper esophageal sphincter function in clinical practice: a primer. Curr Gastroenterol Rep. 2016;18:7.

10. Abou-Nader L, Wilson JA, Paleri V. Transnasal oesophagoscopy: diagnostic management outcomes in a prospective cohort of 257 consecutive cases practice implications. Clin Otolaryngol. 2014;39:108-113

\section{A differential diagnosis of a head and neck bony lesion: Review of a case series with 18 patients with extraintestinal features of familial adenomatous polyposis}

\section{1 | INTRODUCTION}

We would like to draw to the attention of head and neck surgeons the following disease that can present first to head and neck specialists with either a head and neck lump or following an incidental finding on radiological imaging.

Familial adenomatous polyposis (FAP) is a hereditary disease caused by a mutation in the APC gene on chromosome 5 , which is inherited in an autosomal dominant fashion with complete penetrance but variable expression. ${ }^{1}$ However in approximately $25 \%$ of cases, it arises from a de novo mutation of the APC gene. ${ }^{1}$ FAP affects between 1 in 13000 and 18000 live births in the Northern European population ${ }^{2}$ and is characterised by hundreds to thousands of colorectal polyps, which almost inevitably lead to colorectal cancer (CRC) by the age of 35-40 years without a prophylactic proctocolectomy. ${ }^{2,3}$ In the Swedish Familial Adenomatous Polyposis Registry, the median age of diagnosis with CRC was 42 years, and the median age of diagnosis without CRC was 34 , with asymptomatic relatives diagnosed at a median age of 22 years. The average age of progression to colorectal carcinoma is $35-40$ years. ${ }^{2}$ As the disease is multisystem, there are multiple extracolonic manifestations, affecting endoderm, ectoderm and mesoderm layers. Endodermal lesions include intestinal polyps and various carcinomas including thyroid, pancreas, adrenals; ectodermal lesions include the epidermoid cyst, CNS tumours, especially medulloblastomas, desmoid tumours, lipomas and mesodermal lesions include osteomas and dental abnormalities. ${ }^{2,4}$

Among these FAP patients, those with benign extracolonic features such as osteomas, desmoid tumours, epidermoid cysts, or skin fibromas have a subtype named Gardner syndrome, ${ }^{1,5,6}$ originally described by Gardner in 1953. ${ }^{7}$ Another subtype is called Turcot syndrome, in which patients have FAP associated with CNS tumours. ${ }^{2,4}$

FAP should be considered in the differential diagnosis for head and neck lumps, as one of the common features of this disease is osteomas, often multiple, along with soft tissue tumours, which can be found in the head and neck region. ${ }^{2}$ The extraintestinal features of FAP can present many years before the development of symptomatic abdominal polyposis, ${ }^{5,8}$ which can present an excellent opportunity to begin screening and management of the condition.

We present a series of 18 patients with FAP who were found to have osteomas, a proportion of whom were first seen with osteomas by an otolaryngologist-head and neck surgeon, maxillofacial surgeon or dentist. These can either be found incidentally on OPG and referred on, or be referred by primary care as a hard lump in the head and neck region. 


\section{METHODS}

We used the Finnish research registry for FAP, which has recorded all the Finnish cases of FAP, which covers patients and their families since 1963-2017. Included in the registry are 419 patients from 179 families. The FAP patients were diagnosed by endoscopic screening or, from the year 1996 onwards, by genetic testing in combination with endoscopy. Retrospective review of the medical notes of these 419 patients identified the presence of osteomas and site if recorded, date and method of diagnosis of FAP.

Ethics/Permissions: The FAP registry obtains a research permit from the Finnish National Institute for Health and Welfare (Dnro. THL/1068/ 5.05.00/2015) and an institutional Research Ethics Board Approval (Dnro. 104/13/03/02/2015) at the Helsinki University Hospital.

\section{RESULTS}

The FAP registry demographics were 222 (53\%) female, 197 (47\%) male. Median age of diagnosis of FAP was 30 years, range 0-87, interquartile (IQ) range 19-45. A total of 194 patients (46\%) were diagnosed based on symptoms, 142 (34\%) were asymptomatic and diagnosed with colonoscopy screening, and 83 (20\%) were asymptomatic, diagnosed with APC gene analysis.

Osteoma was found in 18 patients, which is $4.3 \%$ of patients in the FAP registry. These patients are described in Table 1 . In six (33\%) of these 18 patients, an osteoma was the first presentation of the disease to a healthcare professional, and they were subsequently diagnosed with FAP. Ten (55\%) had multiple osteomas at presentation, and 8 (45\%) had a solitary osteoma at presentation.

\section{Keypoints}

- Familial adenomatous polyposis (FAP) is an autosomal dominant cancer syndrome.

- FAP can affect most body systems, and patients can develop osteomas and tumours of the skin, which can be detected before the onset on cancer.

- We present 18 patients from a register of 419 patients with FAP who reportedly had an osteoma. Two thirds (94\%) of these patients had osteomas in the mandible or maxilla.

- One-third of the patients with osteomas presented first with the osteomas and were subsequently diagnosed with FAP.

- The presence of osteomas can predate the development of symptoms in FAP by many years.

\section{4 | DISCUSSION}

This was a review of the registry based on the diagnoses available. These FAP patients were not routinely screened radiologically for osteomas; therefore, these findings and diagnoses have been incidental. The patients who were found to have osteomas were of a similar gender distribution to the general FAP population. Patients who presented first with osteomas were diagnosed at a median age of 20 years. Interestingly, there was no significant difference between the ages at diagnosis in the patients who presented first with the osteoma compared to the group with osteomas present.

TABLE 1 Patient demographics and osteoma location

\begin{tabular}{|c|c|c|c|c|}
\hline & & Osteomas present & Osteoma diagnosed first & $\begin{array}{l}\text { Osteomas found after } \\
\text { FAP diagnosis }\end{array}$ \\
\hline $\mathrm{n}=$ & & 18 & 6 & 12 \\
\hline \multirow[t]{2}{*}{ Sex } & Female & 9 & 2 & 7 \\
\hline & Male & 9 & 4 & 5 \\
\hline $\begin{array}{l}\text { Age at presentation when } \\
\text { diagnosed first } \\
\text { with osteoma }\end{array}$ & & & $6,14,15,15,30,38$ & \\
\hline Age at FAP diagnosis & $\begin{array}{l}\text { Range, average, } \\
\text { median }\end{array}$ & $5-57,26.4,21.5$ & $\begin{array}{l}\text { 15-40, 23.3, } 20 \\
\text { (ages corresponding with above } \\
\text { patients: } 21,19,15,15,30,40 \text { ) }\end{array}$ & \\
\hline \multirow[t]{5}{*}{ Osteoma site } & Maxilla & 5 & & \\
\hline & Mandible & $\begin{array}{l}12 \text { ( } 1 \text { of these was later } \\
\text { re-diagnosed as an } \\
\text { osteoblastoma.) }\end{array}$ & & \\
\hline & Frontal bone & 3 & & \\
\hline & Skull & 7 & & \\
\hline & Elsewhere & 2 (forearm, limb) & & \\
\hline \multirow{2}{*}{$\begin{array}{l}\text { Number of } \\
\text { osteomas }\end{array}$} & Multiple & 10 & & \\
\hline & Solitary & 8 & & \\
\hline
\end{tabular}




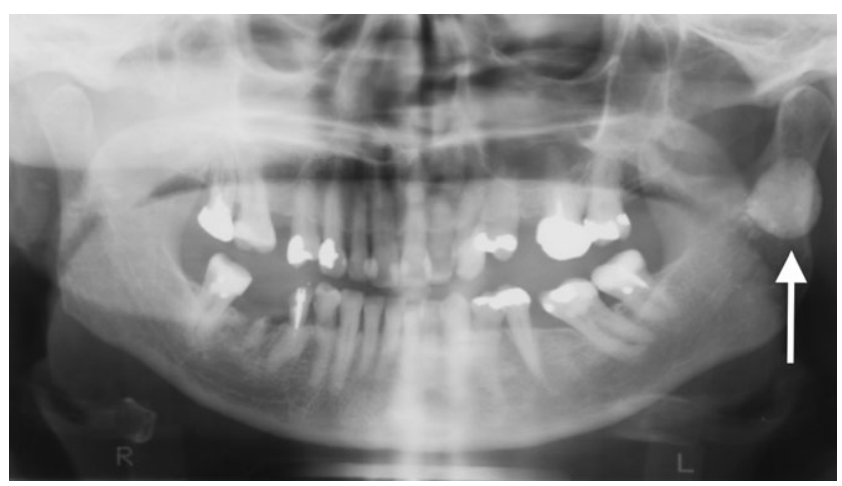

FIGURE 1 Orthopantomogram showing a solitary osteoma of the left mandibular ramus

However, three of the six patients who first presented with osteomas were still not diagnosed with FAP until 2, 5 and 15 years later. In these cases, the diagnosis of FAP would have been possible much earlier if the clinicians were aware of FAP syndrome; however due to the limited sample size, it is difficult to infer whether this is representative.

In our sample, the most common site of osteomas was in the mandible, in keeping with the literature where the angle of the mandible is the most common location. ${ }^{2,9}$ Interestingly, one diagnosed osteoma was later reclassified as an osteoblastoma. Osteoblastoma in FAP has not previously been reported in the English literature.

Patients with osteomas, especially if multiple, or if associated with other soft tissue tumours and/or dental abnormalities should be investigated for FAP, given the severity of the condition and the implications of delayed diagnosis for development of colorectal carcinoma. In our sample $45 \%$ of cases presented with solitary osteomas, therefore, it is worthwhile considering the diagnosis even in this case (eg a solitary osteoma can be seen in Figure 1). Previous reports estimate that $46 \%-93 \%$ of patients with FAP have osteomatous changes of the jaws, ${ }^{8}$ and others report that $61 \%^{5}$ of FAP patients have bony changes associated with the disease of patients with adequate X-ray examination. As the patients in the Finnish registry were not routinely screened for this condition it is probable that a larger proportion has the bony changes. It is imperative that specialists who may be involved in the care may be able to spot extraintestinal manifestations to expedite the diagnosis, especially when the presence of osteomas can signify the first presentation of such a disease.

As osteomas are benign, there are various indications described in the literature for their removal. Suggested indications are if: they interfere with normal function or cause deformity ${ }^{8}$; there is sign of growth in osteomas situated within the sinuses; their location risks obstruction of anatomical drainage sites; they cause symptoms of chronic sinusitis; they risk impinging on important structures such as the orbit. ${ }^{9}$ The imaging modality of choice is thin-slice CT to allow a precise estimation of size and location of the osteoma. ${ }^{8,10}$ From our retrospective case series, we are aware of two of the patients having had surgical treatment for their osteomas. One had a wide frontal bone excision with bony reconstruction using the iliac crest, and the other had the osteoma excised.

Although this is a rare diagnosis, FAP has serious clinical significance especially if missed, as without prophylactic colectomy/proctocolectomy the risk of colorectal cancer is almost inevitable. It is important to ask about osteomas or lumps elsewhere, family history of gastrointestinal pathology, cancers and gastrointestinal symptoms, and to refer to a unit with expertise in the field of this hereditary polyposis if there is any suggestion that this could be FAP. Important symptoms to ask about are weight loss, diarrhoea, mucous discharge, rectal bleeding, abdominal pain or cramping, and anaemia status should also be assessed. ${ }^{8}$ It is advised that patients with FAP undergo bowel, upper gastrointestinal, thyroid and possibly hepatic surveillance given the associated malignancy risk. ${ }^{2,4,8}$

\section{5 | LIMITATIONS}

1. Lack of screening for osteomas, thus it is difficult to know the accurate incidence and locations in this population.

2. Historical nature of the notes. Usually, osteomas were incidental, and little information was written about them.

3. Small sample size.

\section{6 | CONCLUSION}

We want to raise awareness of the presence osteomas and their role in FAP, which is a significant life-limiting disease, so that the patient and family can be screened for this and managed accordingly.

\section{CONFLICTS OF INTEREST}

There are no conflict of interests.

\section{ORCID}

A. Dickinson (iD http://orcid.org/0000-0003-4559-7819

A. Mäkitie iD http://orcid.org/0000-0002-0451-2404

A. Dickinson ${ }^{1}$

L. Koskenvuo ${ }^{2}$

K. Tuomainen ${ }^{1}$

A. Mäkitie ${ }^{1,3}$

A. Lepistö ${ }^{2}$

S. Renkonen ${ }^{1,4}$

${ }^{1}$ Departments of Otorhinolaryngology, Head and Neck Surgery, University of Helsinki, Helsinki University Hospital, Helsinki, Finland

${ }^{2}$ Department of Gastrointestinal Surgery, University of Helsinki, Helsinki University Hospital, Helsinki, Finland

${ }^{3}$ Division of Ear Nose and Throat Diseases, Department of Clinical Sciences, Intervention and Technology, Karolinska Institute and 
Karolinska Hospital, Stockholm, Sweden

${ }^{4}$ Department of Biosciences and Nutrition, Karolinska Institutet,

Stockholm, Sweden

Correspondence

Amy Dickinson, Departments of Otorhinolaryngology, Head and Neck Surgery, University of Helsinki, Helsinki University Hospital, Helsinki,

Finland.

Email: amyjmdickinson@gmail.com

\section{REFERENCES}

1. Fearnhead NS, Britton MP, Bodmer WF. The ABC of APC. Hum Mol Genet. 2001;10:721-733.

2. Galiatsatos P, Foulkes WD. Familial adenomatous polyposis. Am J Gastroenterol. 2006;101:385-398.

3. Bussey HJR. Familial polyposis coli family studies, histopathology, differential diagnosis, and results of treatment. Baltimore: Johns Hopkins University Press; 1975.
4. Groen EJ, Roos A, Muntinghe FL, et al. Extra-intestinal manifestations of familial adenomatous polyposis. Ann Surg Oncol. 2008;15:2439-2450.

5. Jarvinen HJ, Peltokallio P, Landtman M, Wolf J. Gardner's stigmas in patients with familial adenomatosis coli. Br J Surg. 1982;69:718-721.

6. Bisgaard ML, Fenger K, Bulow S, Niebuhr E, Mohr J. Familial adenomatous polyposis (FAP): frequency, penetrance, and mutation rate. Hum Mutat. 1994;3:121-125.

7. Gardner EJ, Richards RC. Multiple cutaneous and subcutaneous lesions occurring simultaneously with hereditary polyposis and osteomatosis. Am J Hum Genet. 1953;5:139-147.

8. Boffano P, Bosco GF, Gerbino G. The surgical management of oral and maxillofacial manifestations of Gardner syndrome. J Oral Maxillofac Surg. 2010;68:2549-2554.

9. Jones $\mathrm{K}$, Korzcak $\mathrm{P}$. The diagnostic significance and management of Gardner's syndrome. Br J Oral Maxillofac Surg. 1990;28:80-84.

10. Lee DH, Jung SH, Yoon TM, Lee JK, Joo YE, Lim SC. Characteristics of paranasal sinus osteoma and treatment outcomes. Acta Otolaryngol. 2015;135:602-607.

\section{Accuracy of FDG PET-CT response assessment following radiotherapy alone for head and neck squamous cell carcinoma: Retrospective analysis of 45 patients}

\section{1 | INTRODUCTION}

Fluorine-18 fluorodeoxyglucose (FDG) positron emission tomography-computerised tomography (PET-CT) is established as an accurate tool for response assessment following concurrent chemoradiotherapy for head and neck squamous cell carcinoma, with a high negative predictive value (NPV), guiding selective surgical intervention. ${ }^{1-3}$ The phase III PET neck surveillance trial demonstrated that PET-CT-guided imaging surveillance following concurrent chemoradiotherapy compared with a planned neck dissection achieved similar survival with far fewer neck dissections and was cost-effective. ${ }^{2}$ However, the addition of concurrent chemotherapy to radiotherapy is often contraindicated due to comorbidity and has not been found to be beneficial to patients with stage I/II disease, age $\geq 70$ years old, WHO performance status $\geq 2{ }^{4}$ There is a paucity of data to determine whether response assessment PET-CT after radiotherapy alone is sufficiently accurate to influence management.

In our centre, we have adopted a policy of observation if a complete metabolic response on PET-CT is achieved following radiotherapy \pm chemotherapy. ${ }^{3,5}$ The aim of this report was to analyse the accuracy of FDG PET-CT response assessment following radiotherapy alone without a planned neck dissection.

\section{2 | METHODS}

\subsection{Ethical considerations}

The study was registered with the Institutional Quality Improvement Board.

\section{2 | Study design}

A total of 45 consecutive patients with head and neck squamous cell carcinoma who underwent FDG PET-CT for response assessment following curative-intent radiotherapy (without chemotherapy) between 2009 and 2014 were retrospectively identified. Inclusion criteria were (i) squamous cell carcinoma of the oropharynx, larynx, hypopharynx or unknown primary, (ii) radiotherapy with curative intent and (iii) FDG PET-CT as a baseline prior to treatment. Patients 